\title{
Reflecting the science of instruction? Screencasting in Australian and New Zealand academic libraries: a content analysis
}

\author{
by
}

\section{Jason Simon Murphy}

Submitted to the School of Information Management,

Victoria University of Wellington

in partial fulfilment of the requirements for the degree of

Master of Information Studies

\section{June 2015}




\section{Abstract}

\section{Research problem}

Instructional screencasts are increasingly part of the online tutorial mix offered by academic libraries, but what makes for effective screencast design? This research provides a snapshot of screencast design in Australian and New Zealand academic libraries and appraises it through the lens of multimedia learning theory.

\section{Methodology}

Evidence-based design principles that promote effective learning for multimedia were identified from the research literature. A cognitive psychological approach was taken, drawing principally from Mayer's cognitive theory of multimedia learning. The principles outlined in Mayer's theory were translated into guidelines applicable to screencast tutorial production. These guidelines formed the basis for an assessment rubric which was applied to screencasts produced by New Zealand and Australian Universities. Content analysis was then applied to determine to what extent screencast tutorials in the sample reflected the principles outlined in Mayer's theory.

\section{Results}

On average, screencasts from the institutions surveyed integrated 7.6 of 9 effective multimedia principles. The low variance across the sample suggests this high standard was approximated or exceeded by most tutorials. Australian and New Zealand libraries were of a comparable standard overall with similar areas of strength and weakness.

\section{Implications}

Mayer's principles provide a useful foundation for designing effective multimedia instruction. The translation of these principles into screencast design guidelines will hopefully serve as useful considerations. Commonly neglected principles (coherence, signalling and segmenting) present areas for design improvement but also opportunities for further research in an academic library context. 
Keywords: screencast, academic libraries, instructional design, multimedia learning, cognitive psychology 


\section{Table of Contents}

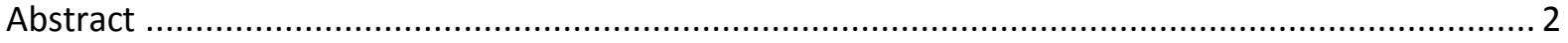

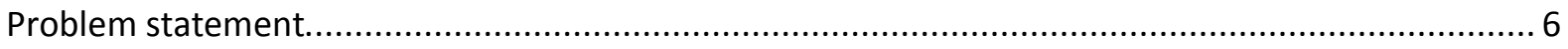

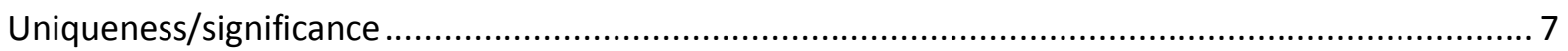

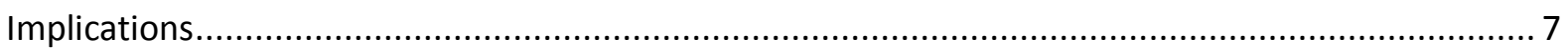

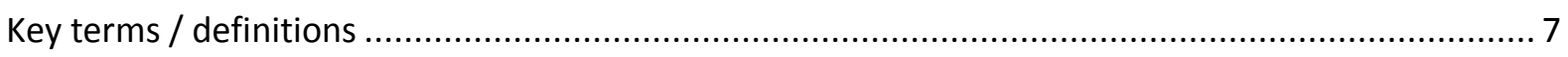

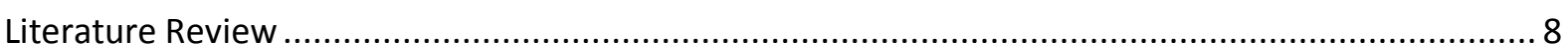

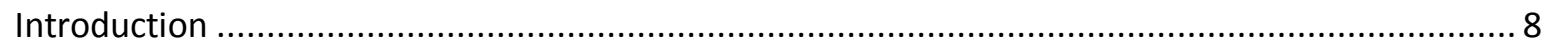

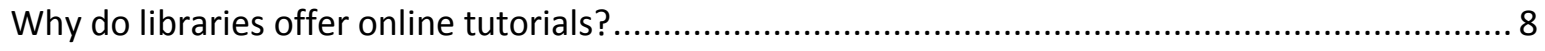

Multimedia video tutorials, screen-capture videos, screencasting? ........................................... 9

What makes for an effective screencast tutorial? ................................................................... 9

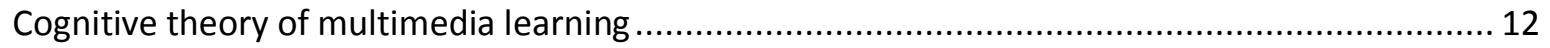

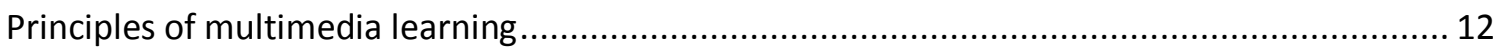

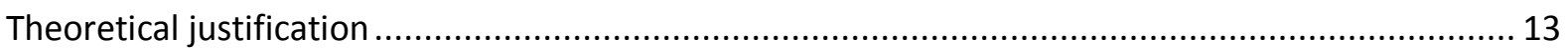

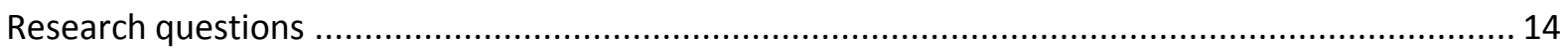

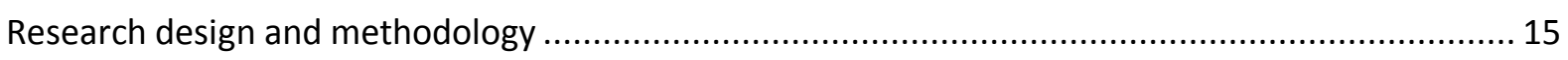

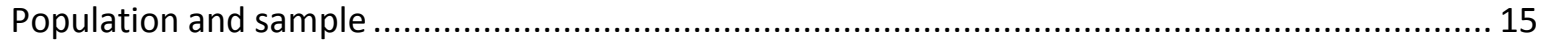

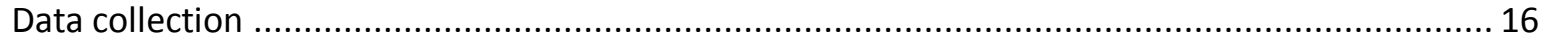

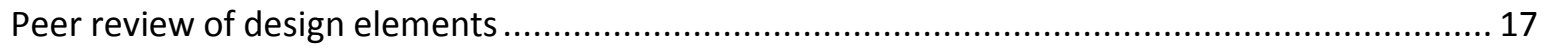

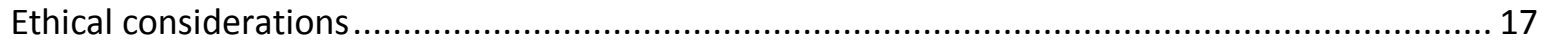

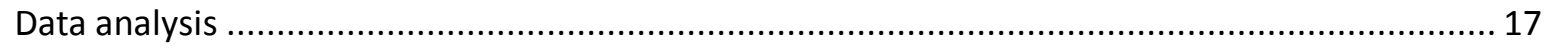

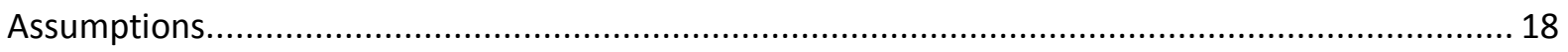

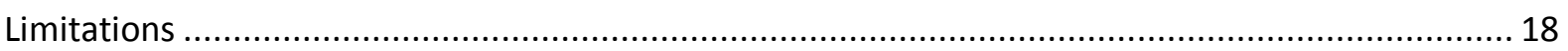

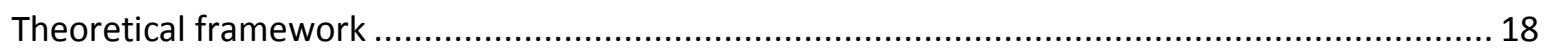

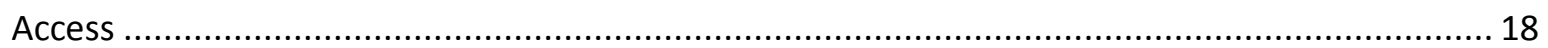

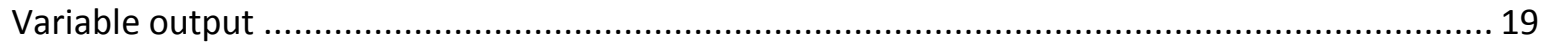

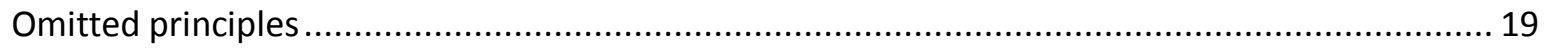

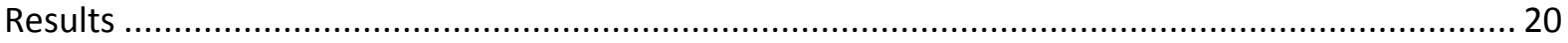

How frequently were the combined principles observed across the sample? ............................ 21

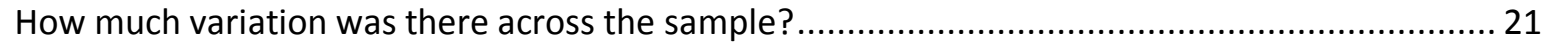

How frequently were the combined principles observed by individual institutions? ..................... 21

How much variation was there across the individual institutions? ................................................ 22 
How frequently was each principle observed across the sample?

Principles for reducing extraneous processing ....................................................... 22

Principles for managing essential processing........................................................ 24

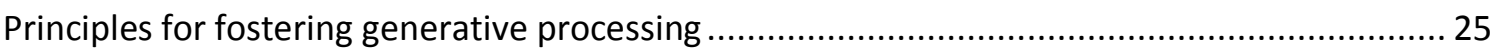

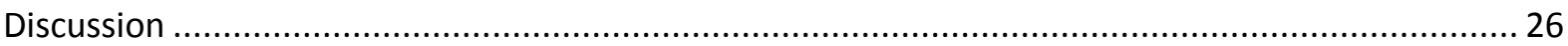

Overall observations........................................................................................ 26

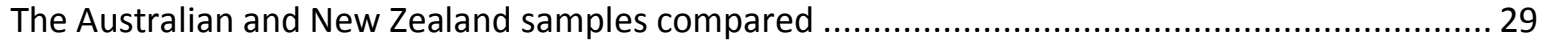

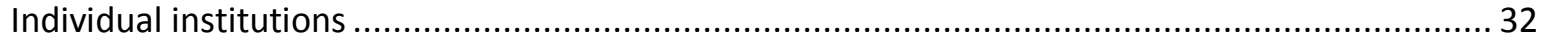

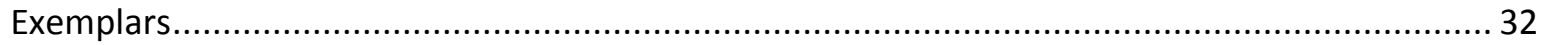

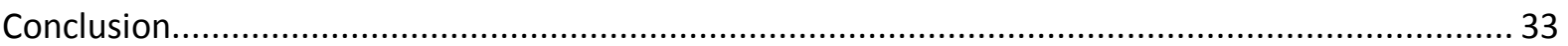

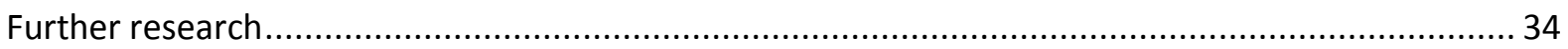

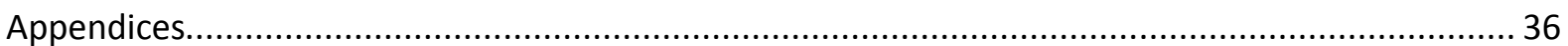

Appendix I: Coding manual for identifying principles......................... Error! Bookmark not defined.

Appendix II: Observed principles by sample: raw numbers and percentages ............................... 40 


\section{Problem statement}

Screencast tutorials (or screencasts) vary in content, production level and the tools used to create them, but simply put are "a digital recording of computer screen activity, often with an audio commentary" (Raftery, 2011, p. 665). Screencasts are commonly used by academic libraries (Cordes, 2011; Ergood, Padron, \& Rebar, 2012), echoing the kinds of instruction often provided in person e.g. using the library catalogue; searching databases (Notess, 2005) and providing research guidance for particular subjects and courses (Ergood et al., 2012).

For those new to screencasting, there is ample advice in the literature on technical and planning considerations (Ergood et al., 2012; Notess, 2005; Plumb, 2010; Raftery, 2011; Slebodnik \& Riehle, 2009; Small, 2010). Less common are guidelines for identifying those design features best proven to facilitate learning. Though there has been extensive research on multimedia learning more generally, there are few articles that outline best practices for screencast tutorials specifically. Those that do, (Betty, 2008; Loch \& McLoughlin, 2011; Oud, 2009; Raftery, 2011; Sugar, Brown, \& Luterbach, 2010), naturally draw recommendations from wider instructional frameworks such as cognitive psychology and educational theory.

This research project:

- Identifies from the research literature evidence-based design principles that promote effective learning for multimedia - in particular it takes a cognitive psychological approach drawing from Mayer's cognitive theory of multimedia learning (Mayer, 2008, 2009; R. E. Mayer, ed., 2014)

- Translates the principles outlined in Mayer's theory into guidelines applicable to screencast tutorial production

- Determines to what extent screencast tutorials currently produced by academic libraries in New Zealand and Australia reflect the principles outlined in Mayer's theory 


\section{Uniqueness/significance}

There is a small international body of literature focused on best-practice design principles for instructional screencasts. Related to this literature are a number of studies that look at how best-practice principles are being reflected in practice. This research adds to the practice-oriented literature by comparing screencasts produced in the New Zealand/Australian academic library context against a multimedia learning framework. To date, there have been few studies looking at online tutorials in this context (Cordes, 2011) and none - to the author's knowledge - focusing on screencasts exclusively.

\section{Implications}

This research provides a snapshot of screencast design in Australian and New Zealand academic libraries from a cognitive psychological viewpoint. Commonly neglected elements of effective design are identified and suggestions for integration into future production. In addition, by identifying a sample of high quality tutorials (i.e. scoring high on the assessment rubric), academic librarians inexperienced in creating screencasts have concrete examples to emulate. Additionally, identifying those libraries that are demonstrating these principles consistently in practice may spur further research into what is driving their approach.

\section{Key terms / definitions}

Cognitive psychology: a branch of psychology concerned with the study of human cognition, "particularly as it affects learning and behaviour" (Cognitive psychology, 2014)

Design element: For the purposes of this study, a design element is an observable, abstractable feature of the screencast e.g. voice narration

Evidence-based best-practice: developing guidelines for effective practice which are "grounded in theory and based on evidence" (Mayer, 2008, p. 760) or as Silber (2010, p. 301) puts it "guided by scientific evidence rather than opinion, ideology or common practice." 
Multimedia learning: Multimedia learning is learning from a combination of words and images. 'Words' includes visual text or narration, while 'images' encompasses static pictures, animation or video (R. E. Mayer, ed., 2014).

Screencast tutorial: an instructional video capturing on-screen computer activity, often with accompanying audio (Raftery, 2011). For the purposes of this project, 'screencast', 'screencast tutorial' and 'instructional screencast' and are considered synonymous.

\section{Literature Review}

\section{Introduction}

This literature review situates screencasts within library online instruction; explores recommendations for effective screencasts, and highlights research approaches that evaluate their design. It also summarises Mayer's cognitive theory of multimedia learning and explains why this has been chosen as an evaluative framework for this study.

Academic libraries have a long history of using computer-aided instruction, reaching back to the late 1960s (Ergood et al., 2012). However, the fact that creating tutorials required specialist skills and hardware proved to be a barrier to widespread use. By the mid-1990s, this began to change with the emergence of the World Wide Web. Soon after, a number of academic libraries began to experiment with creating and delivering tutorials online. An early example of this was PLUTO (Purdue Libraries Undergraduate Tutorial Online), targeting first-year students, with a library orientation and introduction to database searching (Scholz, Kerr, \& Brown, 1996). Almost a decade later, web-based tutorials have become thoroughly mainstream in academic libraries (Mestre, 2012).

\section{Why do libraries offer online tutorials?}

Partly this is due to the relative ease with which they can now be created. The rise of webauthoring tools (e.g. WordPress), means specialist knowledge is no-longer required to create basic web content. Apart from this, other factors cited include: increased demand for distance learning (Blummer \& Kritskaya, 2009) expectations from students accustomed to 
online on-demand content (Dewan \& Steeleworthy, 2013) and limited opportunities (and resources) for in-person contact (Arant-Kaspar \& Benefiel, 2008).

In terms of content, library tutorials vary across institutions but a number of major themes can be identified. For example information literacy concepts, academic tools, search strategies and library resources and services (Somoza-Fernández \& Abadal, 2009; Su \& Kuo, 2010).

So, online tutorials are expedient, but are they effective? In principle, the answer seems to be yes, with a number of studies suggesting they can be as effective as face-to-face classes (Anderson \& May, 2010; Silver \& Nickel, 2005; Zhang, Watson, \& Banfield, 2007).

\section{Multimedia video tutorials, screen-capture videos, screencasting?}

Screencasts are referred to in the literature by various names, but this is the name that appears to have stuck (Cordes, 2011; Ergood et al., 2012; Oud, 2009; Tewell, 2010). As a term, screencasting was popularised by technology journalist Jon Udell after crowd sourcing suggestions from the readers of his blog (Udell, 2004b). As Udell noted at the time, the technology had been around for at least a decade (Good, 2006). The difference now was that increased access to broadband and low-cost screen-recording software was promising to "democratize the use of screen videos" (Udell, 2004a). What had previously been the domain of instructional designers and product developers was now in the hands of anyone

with a computer and broadband connection. Screencasts are now a widespread and popular method of online instruction and are increasingly part of the tutorial mix in academic libraries (Cordes, 2011; Oud, 2009; Tewell, 2010).

\section{What makes for an effective screencast tutorial?}

There are a number of instructional approaches that can be taken when designing screencasts. This section looks at some attempts to define effective multimedia instruction more generally, along with recommendations specific to screencasting.

There are two main approaches within the literature for establishing best-practice guidelines. The first is to take an instructional theory (or theories) and derive from these the elements needed for effective instruction (Cordes, 2011; Mayer, 2009; Oud, 2009; 
Tempelman-Kluit, 2006; Tewell, 2010). The second is to look at tutorials delivered in practice, and identify elements that appear to work well or need to be improved (BowlesTerry, Hensley, \& Hinchliffe, 2010; Oehrli, Piacentine, Peters, \& Nanamaker, 2011; Sugar et al., 2010). Examples of both are discussed below.

Templeman-Kluit (2006) is of interest as an early attempt to link multimedia theory with library practice. The aim was to determine the effectiveness of HTML versus "streaming media" as a teaching tool. Drawing from cognitive psychology (cognitive load theory (CLT), Paivio's dual-coding theory and Mayer's cognitive theory of multimedia learning) and constructivism, Tempelman-Kluit identified a list of multimedia principles that support learning. This identification of cognitive psychology (cognitive load theory) and constructivism as relevant theoretical lenses is echoed in subsequent research (Morris \& Chikwa, 2014; Morrison, Ross, Kalman, \& Kemp, 2013; Oud, 2009). The conclusion of this comparison was that a streaming media tutorial better reflects these multimedia learning principles - and is therefore more likely to be effective - than the same tutorial in HTML.

Oud (2009) draws from research in cognitive psychology and educational theory to develop a best practice checklist for effective screencast instruction. Like Templeman-Kluit, she also cites cognitive load theory as an important theoretical lens. While not explicitly mentioned, statements such as "learning is an active, interactive process where learners make meaning from new experiences" (p. 169) are indicative of a constructivist approach (Cooperstein \& Kocevar-Weidinger, 2004). Synthesising research from cognitive psychology and educational theory, Oud presents five overarching principles for effective screencasts: ask whether multimedia is needed; minimise cognitive load; include interactivity; promote critical thinking and know your students. Other multidisciplinary best-practice articles exist (Blummer \& Kritskaya, 2009) but Oud's stands out in the literature for focusing on screencasts rather than online instruction more generally.

Tewell's aim was to review the nature and quality of online tutorials (including screencasts) offered by academic art libraries and identify potential areas for improvement (2010, p. 54). There was no stated theoretical underpinning to Tewell's survey of online video tutorials in academic art libraries. However, he references three sources as the basis for his best 
practice criteria (Blummer \& Kritskaya, 2009; Oud, 2009; Smith, 2010). Tewell does not specify which elements he has taken from each, but some aspects associated with Mayer's multimedia theory (integration of video, audio and text; segmenting topics) are identifiable. The majority of his criteria however are usability-focused, technical and/or aesthetic e.g. "is the visual information presented in an attractive...manner"; "is unwanted background noise audible?"; “which recording software was chosen, if appropriate?" (2010, p. 61).

Tewell found about half of the 290 art libraries he surveyed were offering instructional videos. Of the 1070 original videos identified, screencasts were the most popular type comprising $72.7 \%$ (778). On average, libraries performed best in the areas of design and video quality (3.47/5 and 3.09/5), but were weaker in usability (2.91), content (2.84) and audio quality (2.71).

The main objective of Cordes' (2011) research was to explore whether any statistically significant relationships exist between the LIS literature on online tutorials and academic library practice in New Zealand and Australia. Those relationships could then potentially indicate the relevance of published research to Australian and NZ practice. Though focused on online tutorials generally, screencasts made up the majority of the sample at $71 \%$.

Several theoretical frameworks were explored, with elements ultimately being selected with reference to the principle of least effort. This theory suggests that individuals will seek to "minimise the estimated average rate of work for any task in any situation" (p. 16). No statistically significant differences were detected between design elements in the literature and the sampled online tutorials. However, the limited size of the literature sample (27 articles) raised some doubt over the conclusiveness of the results (p. 5).

Complementing the theory-first approach, a number of studies have assessed screencast tutorials in practice, using observation, learner engagement and feedback to suggest or endorse best-practice design principles. Recommendations vary, but cited frequently is the suggestion to keep videos short (up to several minutes in length) or divide up longer segments (Bowles-Terry et al., 2010; Guo, Kim, \& Rubin, 2014; Mestre, 2012; Morris \& Chikwa, 2014; Oehrli et al., 2011). Other recurring recommendations include allowing learners to control the pacing of instruction (Mestre, 2012; Raftery, 2011); simplicity - keep information directly focused on the instruction; avoid inessential or distracting elements 
(Bowles-Terry et al., 2010; Hess, 2013; Loch, Jordan, Lowe, \& Mestel, 2013) and presenting in an informal style (Guo et al., 2014; Small, 2010).

\section{Cognitive theory of multimedia learning}

Mayer's work has two principal objectives which are to explain how people learn from multimedia (2009, p. 266; 2011b, p. 427) and to improve multimedia instruction by identifying principles of effective design $(2009$, p. 266$)$. This has resulted in his cognitive theory of multimedia learning, which continues to develop based on his own and colleagues' research. He draws on previous and contemporary research in cognitive psychology including Paivio's dual coding theory, Baddeley's working memory model, Sweller's cognitive load theory (Reed, 2006) and constructivist learning theory (Mayer \& Moreno, 2002). Multimedia instruction is defined by Mayer as, "the presentation of material using both words and pictures, with the intention of promoting learning" (2009). 'Words and pictures' may bring to mind a static representation, but Mayer's intention is broad here, including video and verbal narration. The principles are therefore applicable to screencasts.

\section{Principles of multimedia learning}

The theory is founded on three basic principles, which include (Clark \& Mayer, 2011b):

1. Dual channels - words and pictures are processed by different parts or 'channels' within the brain

2. Limited capacity - new information is held in working memory before being processed and learned. The amount of information that can be held in working memory at any one time is limited. Overburdening this capacity results in 'cognitive overload' which reduces effective processing.

3. Active processing - in order for learning to be meaningful, people need to cognitively engage with the material. This involves paying attention to relevant information, mentally organising and representing the information and integrating it with existing knowledge. Effective multimedia instruction, according to this theory, will need to take into account these features and limitations of human information processing. 
Mayer (2009, 2011a; 2014) identifies a number of principles for effective multimedia instruction with practical recommendations. In this view, effective instruction enables the optimal cognitive processing of information. In summary, people learn best from multimedia when the design can:

- Reduce extraneous processing - remove those elements which are unnecessary or an impediment to the learning objectives

- Manage essential processing - enabling the learner to select and mentally represent the instructional material

- Foster generative processing - enabling the learner to make sense of the material and integrate it into existing knowledge

Each of these instructional goals is served by sub-principles with suggested actions. These sub-principles form the basis for identifying design elements for this research project (see Appendix I for a list of the principles used in this study).

\section{Theoretical justification}

Considering the literature cited above, why focus on Mayer's multimedia theory as a critical lens? Though best-practice recommendations typically draw from multiple frameworks, aspects of Mayer's theory are frequently integrated (Loch et al., 2013; Oud, 2009; Raftery, 2011; Scales, Nicol, \& Johnson, 2014; Tempelman-Kluit, 2006). In addition to being grounded in evidence-based research, many of the recommendations are increasingly recognisable in common practice and the practice literature cited above e.g. presenting information in short segments (segmenting principle) and using informal language and a conversational style (personalisation principle). Mayer's principles also benefit from relative simplicity, requiring less interpretation than some other rubrics (or at least elements of them) in this review e.g. Tewell (2010). For example, the placement of "printed words near corresponding graphics" (Mayer, 2011b, p. 436) is clearly identifiable whereas information being presented in "an attractive and effective manner"(Tewell, 2010, p. 61) is less so. Also, the focus is on observable design elements, rather than contextual information such as intended audience, pre-existing knowledge of viewers etc. Not to say this information is not useful or essential in planning - it is - but it is not likely to be discoverable through third- 
party content-analysis. As Oud points out, there are a number of other factors that contribute to the effectiveness of screencasts, but the cognitive psychological approach is important for "creating clear, focused multimedia tutorials that are easy to understand and remember" (Oud, 2009, p. 168). For all of the above reasons, Mayer's approach provides a convincing (if not exhaustive) foundation for effective screencast tutorial design.

\section{Research questions}

To what extent do screencasts currently produced by academic libraries in New Zealand and Australia reflect the principles outlined in Mayer's multimedia learning theory?

In order to answer this question, the following questions are asked:

- How frequently are the combined design elements observed amongst the sample?

- How frequently is each design element observed amongst the sample?

- Which design elements are least represented amongst the sample?

- Which design elements are most often represented amongst the sample?

The questions are applied to:

- All screencasts in the sample

- Screencasts by country

- Screencasts by institution

What is the significance of making these distinctions? Testing all screencasts in the sample provides a broad answer to the principal research question. As for the other two distinctions (country / institution), the interest here is to uncover any significant disparities between the sampled countries or institutions. This project won't provide easy answers for why that is the case (if it is), but it may provide impetus for further qualitative research. 


\section{Research design and methodology}

This research takes a quantitative approach, employing a cross-sectional research design. Taking Bryman's definition (Bryman, 2012, p. 58), a cross-sectional design collects data on "more than one case", "at a single point in time" in connection with "two or more variables."

Precedents for this approach, in a similar context, include Cordes (2011) and Tewell (2010), as previously mentioned. Like this project, they share a need to compare a theoretical framework to online tutorials in practice. Their basic approach - a cross-sectional quantitative content analysis using a coding schedule of design elements - was therefore considered a good model for this project.

The research methods employed:

- Use Mayer's principles of multimedia learning to create a list of effective design elements. These design elements form the categories of an assessment rubric.

- Gather and analyse a sample of screencasts produced by academic libraries in New Zealand and Australia. Content analysis was used to "quantify content in terms of predetermined categories" (Bryman, 2012, p. 90). For this study that means noting the presence or absence of features identified in the assessment rubric.

- Use descriptive statistical analysis to observe the relationship between best-practice recommendations and screencast production at overall (NZ and Australia combined), national (NZ and Australia compared) and institutional levels.

\section{Population and sample}

This study uses screencasts produced by libraries within 16 universities - New Zealand's eight universities ("The NZ University System," 2014) and Australia's ‘Group of 8’ (Go8) (Group of Eight Australia, 2014). Though there are 39 universities within Australia, limiting to the Go8 works for reasons of symmetry ( 8 NZ and 8 Australian universities) and pragmatism for a small scale project. In defense of limiting to the Go8, they account for two thirds of Australian university research activity and cover a broad range of general and professional disciplines. This strategy echoes that of Cordes' (2011) who had a similar focus, looking at practice within NZ and Australian academic libraries. Given the shared scale, 
geographical focus and time constraints of both projects, using the same population makes sense.

To qualify as a screencast and therefore for inclusion in the sample, videos needed to:

- be created by the library for their users i.e. not merely a link to another institution or vendor's content

- be comprised of screencapture content for at least $50 \%$ of their total duration

- feature instruction in a library-specific product or service

For practical reasons, only those screencasts that are publicly available have been included. Whether all screencasts were to be assessed, or just a representative sample was determined by a) the number of screencasts available and b) the amount of time practicably available for assessing them. For this reason, an initial pilot sample was taken to establish an average assessment time. The number of available tutorials, average time taken for the sample and time available meant that all tutorials were able to be assessed.

\section{Data collection}

Screencasts were identified from the university library websites, documented and linked to within an excel spreadsheet. The methods of identification included:

- Keyword searching within each website e.g. 'screencast', 'tutorial', 'video'

- Using Google site search to search library domains e.g. site: site:library.victoria.ac.nz/library-v2/ video

- Follow links to help/tutorial sections within library websites e.g. http://library.victoria.ac.nz/library-v2/research-and-study-help

- Contacting individual institutions where necessary

A coding schedule, based on Mayer's design principles, was created to gather data for content analysis. Each screencast was viewed and scored for the presence or absence of each design element in the assessment rubric. A ' 1 ' or ' 0 ' stands for the presence or absence of each element respectively. A score of 0.5 was assigned where an element has been partially fulfilled. See Appendix I: Coding manual for identifying principles. 
One criticism of Tewell's approach is the author's use of a 1-5 rating scale (poor to exceptional) to determine quality across a range of criteria - content; usability; design quality; video quality; audio quality and duration. Given the author was the only rater, simplifying the criteria and noting merely the presence or absence of qualities as per Cordes (2011, p. 44) would have been less subjective, if also less nuanced. For this reason, the simplified approach has been used in this study.

\section{Peer review of design elements}

To encourage internal validity, a small sample peer review was used to confirm that the design elements could be similarly identified by different raters (Cordes, 2011, p. 10). Using the coding guidelines in Appendix I, a colleague and I independently rated the same sample of screencasts. The scoring was compared and any discrepancies noted. This resulted in a clarification of the principle descriptions to reduce ambiguity and highlighted the difficulty of consistently applying the pre-training principle (see Omitted Principles below). As a result, this principle was excluded from from the rubric.

\section{Ethical considerations}

This study focuses on publicly available data. For this reason, human ethics approval was not required.

\section{Data analysis}

Descriptive analysis is used to address the research questions. Calculations include:

- An overall scoring (mean frequency of combined design elements) at the institutional, national (NZ/Australia) and sample (all screencasts) level

- Frequency and percentage of each design element at the national and sample level

- Variation (standard deviation) amongst institutions and across the entire sample

From this data, patterns can be identified at the institutional, national and international level, potential areas for improvement highlighted and exemplars identified.

Again, Cordes (2011) and Tewell (2010) provide some precedent here, both mapping the frequency of particular design elements within a sample of tutorials. In the case of Cordes, this extended to statistical analysis used to a) identify the frequency with which selected 
design elements featured within the literature compared to tutorials in practice and $b$ ) determine if any of these relationships were statistically significant.

Tewell used quantitative content analysis to create an inventory of the types of videos produced by academic art libraries as well as assessing them for quality. Descriptive statistics were used to identify trends and themes.

This study is interested in the frequency with which the chosen design elements appear within the sampled screencasts, but not with how frequently the principles appear in the literature. For this reason, it is more reflective of Tewell's approach.

\section{Assumptions}

The assessment framework in this study rests on principles of effective multimedia instruction established through cognitive psychological research. It is assumed, given the generalisability of these principles, that these can be usefully applied to screencast design.

\section{Limitations}

\section{Theoretical framework}

This research looks at effective screencast design through the lens of one particular theory Mayer's cognitive theory of multimedia learning. Though backed by significant research, it is acknowledged that a number of other factors contribute to the effectiveness of screencast instruction in practice (Blummer \& Kritskaya, 2009; Ergood et al., 2012; Stiwinter, 2013). For this reason, while screencasts that reflect multimedia learning principles can be expected to provide an excellent foundation for effective learning, they provide no guarantee in the absence of other factors e.g. discoverability, adequate student motivation etc. Also, not all the principles that appear throughout Mayer's work have been included, for reasons discussed below (see Omitted Principles).

\section{Access}

Some institutions restrict the number of tutorials that are publicly available. In some cases, for example, a set of tutorials might be associated with a particular course and only available within a learning management system (e.g. Blackboard). Not having privileged 
access to these tutorials, only those that were openly accessible have been considered. For this reason, judgements on any particular institution's screencast output may be incomplete.

\section{Variable output}

The university libraries in this sample varied considerably in the number of screencasts produced, from zero (University of New South Wales) to 41 (University of Otago). Additionally, the New Zealand sample (124 screencasts) was significantly larger than the Australian (29 screencasts). It is hard to account definitively for the disparity, but as mentioned above, access is not universal with some institutions restricting the public availability of some tutorials. Also, as mentioned in the results below, a number of institutions, particularly in Australia, appear to be moving toward animated tutorials rather than screencasts for online instruction. As a result, the data analysis can only provide a snapshot of the available sample, rather than establishing significance or making statistical inferences about screencasting practice in Australian and New Zealand as a whole.

\section{Omitted principles}

Four principles that appear in some iterations of Mayer's theory (Mayer, 2008; R. E. Mayer, 2014a) - expectation, image, embodiment and pre-training - have been intentionally omitted.

The expectation principle is the idea that "people learn better when they are shown the type of test items in advance of the lesson." (R. E. Mayer, 2014a, p. 392). The reason for excluding this principle is that it does not appear in most major iterations of Mayer's theory (R. E. Mayer, ed., 2014) (Clark \& Mayer, 2011b; Mayer, 2009) and library screencast tutorials, typically do not involve post-testing. What library screencasts do sometimes include, is a statement of the learning objectives (Deakin University, 2013). Presenting learning objectives at the beginning of a presentation is possibly supported by the expectation principle, but more research is needed to establish how effective this is (R. E. Mayer, 2014a).

The image principle states that adding an image of the instructor, "such as a talking head or motionless cartoon character" (R. E. Mayer, 2014a, p. 395) to a multimedia presentation does not significantly improve learning. The embodiment principle suggests that if a 
representation of the instructor is used, adding "human-like gesturing" (R. E. Mayer, 2014a, p. 395) may be more effective. The reason for omitting these principles is that most library screencasts do not typically use an image of the narrator, and where they do, there is not yet compelling evidence either way for its effectiveness (R. E. Mayer, 2014a).

Finally, the pre-training principle considers that people learn more deeply when they are familiar with "the names and characteristics of the main concepts (Mayer, 2009, p. 189)." The idea is that some familiarity with the elements of a lesson will free up cognitive capacity for processing how everything fits together. A common example given is that of a lesson on how an engine works. With some familiarity with each part of the engine and its basic function, the learner's cognitive capacity can be focused more on the causal process. At first glance, this appears translatable to the library instruction scenario. For example, a screencast on advanced searching could plausibly be helped by some pre-training in the available fields and layout of the library catalogue / discovery search.

Initially I had included the principle, but abandoned it after a number of difficulties in consistently applying it. First, videos from the institutions in this project were mostly standalone tutorials. If they were linked together, it was usually by virtue of them all being tutorials, rather than being part of a series, each building on the next. For this reason, it was not easy to tell if some videos were intended (or could be considered) as pre-training for other tutorials. Second, from the existing experimental data, it is not easy to determine what level of introductory material is sufficient to count as pre-training in this context. For example, is simply outlining the key concepts to be covered enough? Sticking with the catalogue/discovery example, would it need to be a stand-alone module going through the separate on-screen elements or would integrating this orientation-type material into the main instruction work just as well? Lacking clear answers to these questions precluded me from continuing with them as testable principles, but it highlights a possible area for information studies research in future.

\section{Results}

A total of 153 screencast tutorials were identified after searching the 16 university library websites. The majority of available tutorials were produced by the New Zealand university 
libraries (124) with 29 tutorials sourced from Australian Go8 libraries. With the exception of University of New South Wales, all of the libraries surveyed produced one or more instructional screencasts as defined by this project. It was interesting to note that some institutions (mostly from the Australian sample) appeared to be moving away from screencasts and into animation-based tutorials with little to no screencapture content (University of New South Wales Library, 2015; University of Sydney Library). While the assessment rubric could certainly have been applied to these tutorials, there were a couple of reasons for excluding them. First, strictly speaking they fell outside of the screencast definition as stated and second they were arguably different enough to risk muddying efforts at comparison.

Each tutorial in the sample was rated against an assessment criteria comprised of nine principles. Each of these principles corresponds to Mayer's instructional goals for effective multimedia learning which are to:

- Reduce extraneous processing

- Manage essential processing

- Foster generative processing

For each principle, the tutorial received a rating of 1 (observed), 0.5 (partially observed) or 0 (not observed). In each case this yielded a total possible score ranging from 0 to 9.

\section{How frequently were the combined principles observed across the sample?}

The average score for all tutorials combined was $7.63 / 9$ or $85 \%$. At the national level, the New Zealand sample had a combined average of 7.58 / 9 or $84 \%$, while Australian tutorials were rated slightly higher on average at 7.88 / 9 or $88 \%$.

\section{How much variation was there across the sample?}

Across all screencasts there was a standard deviation of 0.94 .

\section{How frequently were the combined principles observed by individual} institutions?

\begin{tabular}{|l|r|r|}
\hline Institution & Average & Percentage \\
\hline Australian National Library & 8.5 & 94.44 \\
\hline
\end{tabular}




\begin{tabular}{|l|r|r|} 
Auckland University of Technology & 8.34 & 92.67 \\
\hline University of Queensland & 8.31 & 92.33 \\
\hline University of Waikato & 8.2 & 91.11 \\
\hline University of Sydney & 8 & 88.89 \\
\hline University of Melbourne & 7.79 & 86.56 \\
\hline University of Western Australia & 7.67 & 85.22 \\
\hline Victoria University of Wellington & 7.57 & 84.11 \\
\hline Massey University & 7.5 & 83.33 \\
\hline University of Otago & 7.28 & 80.89 \\
\hline University of Auckland & 7.08 & 78.67 \\
\hline University of Canterbury & 6.9 & 76.67 \\
\hline University of Adelaide & 6 & 66.67 \\
\hline Lincoln University & 5.75 & 63.89 \\
\hline Monash University & 5.5 & 61.11 \\
\hline
\end{tabular}

\section{How much variation was there across the individual institutions?}

For average scoring by institution there was a standard deviation of 0.96 .

\section{How frequently was each principle observed across the sample?}

Brief explanations of each multimedia learning principle follow, along with results at the overall and national level. These summaries are drawn principally from Clark \& Meyer (2011b) and Mayer (2008, 2009; 2014c; 2014). For further practical guidelines used in applying the principles, see Appendix I.

\section{Principles for reducing extraneous processing}

\section{Coherence}

The coherence principle is that people learn better from a multimedia lesson when extraneous material is excluded. In other words, if words, images or sounds are not directly related to the instructional objectives, they should be excluded. The rationale is that it can be harder for the learner to focus on the essential material if other information is competing for their attention. Examples of extraneous material might include sound effects, background music or interesting, but inessential pictures/graphics.

Percentage of tutorials observing the coherence principle

\begin{tabular}{|l|r|r|r|}
\hline Tutorial sample & \multicolumn{1}{|l|}{ Observed } & Partially observed & Not observed \\
\hline All & 61.44 & 26.80 & 11.76 \\
\hline Australian & 65.52 & 34.48 & 0.00 \\
\hline New Zealand & 60.48 & 24.19 & 15.32 \\
\hline
\end{tabular}




\section{Signalling}

The signalling principle is that people learn better from a multimedia lesson when the essential material and its organization are highlighted. The rationale is that people will learn more efficiently if their attention is directed to the most important material, rather than having to separate it out themselves.

Examples could include introducing how the lesson is organised and/or visual or aural cues for example, spotlighting, arrows, headings or voice emphasis on important points.

Percentage of tutorials observing the signalling principle

\begin{tabular}{|l|r|r|r|}
\hline Tutorial sample & \multicolumn{1}{|l|}{ Observed } & Partially observed & Not observed \\
\hline All & 70.59 & 29.41 & 0.00 \\
\hline Australian & 79.31 & 20.69 & 0.00 \\
\hline New Zealand & 67.74 & 32.26 & 0.00 \\
\hline
\end{tabular}

\section{Redundancy}

The redundancy principle is that people learn better from a multimedia lesson with graphics and narration, rather than graphics, narration and on-screen text. The rationale here is that by duplicating spoken and written text, there is a risk of overloading people's processing capacity by either a) causing them to scan between what is written on screen and the visual images and/or b) prompting unnecessary mental effort in comparing the spoken and printed information.

An example of redundancy would be adding captions to a screencast that duplicate (or mostly duplicate) the spoken narration.

Percentage of tutorials observing the redundancy principle

\begin{tabular}{|l|r|r|r|}
\hline Tutorial sample & \multicolumn{1}{|l|}{ Observed } & Partially observed & Not observed \\
\hline All & 82.35 & 13.07 & 4.58 \\
\hline Australian & 86.21 & 13.79 & 0.00 \\
\hline New Zealand & 81.45 & 12.90 & 5.65 \\
\hline
\end{tabular}

\section{Spatial contiguity}

The spatial contiguity principle is that people learn better from a multimedia lesson where corresponding words or graphics appear in close proximity to each other. The idea here is reduce cognitive resources spent scanning between words and corresponding graphics to match them up.

For example, a statement describing the next step in the instruction e.g. "click the red button" would be placed near the red button on the screenshot.

Percentage of tutorials observing the spatial contiguity principle 


\begin{tabular}{|l|r|r|r|}
\hline Tutorial sample & \multicolumn{1}{l|}{ Observed } & \multicolumn{1}{l|}{ Partially observed } & Not observed \\
\hline All & 98.04 & 1.96 & 0.00 \\
\hline Australian & 100.00 & 0.00 & 0.00 \\
\hline New Zealand & 97.58 & 2.42 & 0.00 \\
\hline
\end{tabular}

\section{Temporal contiguity}

The temporal contiguity principle is that people learn better from a multimedia lesson when corresponding images and narration are presented simultaneously rather than successively. For example, in a screencast demonstrating a sequence of actions (e.g. making an online interloan request), the narration should be timed to match the actions occurring on screen. The rationale is that in presenting the images and narration simultaneously, it is easier for the learner to hold both streams of information in their working memory. This theoretically should assist the learner in making mental connections between the auditory and visual information.

Percentage of tutorials observing the temporal contiguity principle

\begin{tabular}{|l|r|r|r|}
\hline Tutorial sample & \multicolumn{1}{|l|}{ Observed } & Partially observed & Not observed \\
\hline All & 88.24 & 11.76 & 0.00 \\
\hline Australian & 86.21 & 13.79 & 0.00 \\
\hline New Zealand & 87.90 & 12.10 & 0.00 \\
\hline
\end{tabular}

\section{Principles for managing essential processing}

\section{Segmenting}

The segmenting principle is that people learn better from a multimedia lesson when it is divided into smaller, user-paced segments rather than as a continuous whole. For example, a multi-part lesson might pause between topics, with the user having control of when to continue to the next segment. The rational here is that by breaking up longer instruction, you give learners more time to process the information before moving on, hence reducing the chance of overload.

Percentage of tutorials observing the segmenting principle

\begin{tabular}{|l|r|r|r|}
\hline Tutorial sample & Observed & Partially observed & Not observed \\
\hline All & 9.80 & 90.20 & 0.00 \\
\hline Australian & 6.90 & 93.10 & 0.00 \\
\hline New Zealand & 9.68 & 90.32 & 0.00 \\
\hline
\end{tabular}

\section{Modality}

The modality principle is that people learn better from a multimedia lesson when it uses spoken words rather than printed text. The rationale here is that verbal and visual information is processed by different cognitive channels, which are each limited in capacity. 
Printed text and images are both considered to be visual channel dependent, so providing spoken narration frees up visual processing power. This additional capacity can be used to better process the images being presented.

Percentage of tutorials observing the modality principle

\begin{tabular}{|l|r|r|r|}
\hline Tutorial sample & \multicolumn{1}{|l|}{ Observed } & Partially observed & Not observed \\
\hline All & 84.97 & 0.65 & 14.38 \\
\hline Australian & 89.66 & 0.00 & 10.34 \\
\hline New Zealand & 84.68 & 0.81 & 14.52 \\
\hline
\end{tabular}

\section{Principles for fostering generative processing}

\section{Personalisation}

The personalisation principle is that people learn better from a multimedia lesson when it is presented in a conversational rather than formal style. The rationale is that informal, language is more likely to make people feel a sense of rapport or "social presence" (Mayer, 2009 , p. 244). Where this is the case, people will try harder to make sense of what the presenter is saying. Examples might include using "you" and "your" rather than the more impersonal "the"; not using jargon or obscure words where a simpler or more commonplace term might describe things equally well. This should not be so casual as to distract from the lesson and in fact can be quite subtle. For example using "a few first and second person pronouns, or a friendly comment (Clark \& Mayer, 2011a, p. 188)."

Percentage of tutorials observing the personalisation principle

\begin{tabular}{|l|r|r|r|}
\hline Tutorial sample & \multicolumn{1}{|l|}{ Observed } & Partially observed & Not observed \\
\hline All & 93.46 & 3.92 & 2.61 \\
\hline Australian & 96.55 & 3.45 & 0.00 \\
\hline New Zealand & 93.55 & 4.84 & 1.61 \\
\hline
\end{tabular}

\section{Voice}

The voice principle is that people learn better from a multimedia lesson when any narration is spoken in a human rather than a machine-generated voice. As for the personalisation principle, using a human voice is more likely to build rapport or social presence between the listener and presenter.

Percentage of tutorials observing the voice principle

\begin{tabular}{|l|r|r|r|}
\hline Tutorial sample & \multicolumn{1}{|l|}{ Observed } & Partially observed & Not observed \\
\hline All & 85.62 & 0.00 & 14.38 \\
\hline Australian & 89.66 & 0.00 & 10.34 \\
\hline New Zealand & 85.48 & 0.00 & 14.52 \\
\hline
\end{tabular}




\section{Discussion}

\section{Overall observations}

Looking at the overall sample, the first thing that can be noted is the relatively high scoring against the principles, with an average of 7.63 / 9 (85\%). The low standard deviation across the entire sample indicates that this standard (or something close to it) was observed by most tutorials. Breaking this down further, comparing Australian and New Zealand tutorials, Australia was slightly higher than average on $88 \%$ compared with NZ slightly below at $84 \%$. So, at the macro level, effective multimedia learning principles are being well observed. Looking more closely at the frequency with which each principle was observed, we can identify possible areas for improvement.

Percentage of tutorials observing each principle, ordered from highest to lowest

\begin{tabular}{|l|r|r|r|}
\hline Principle & Present & Partially present & Not present \\
\hline Spatial Contiguity & 98.04 & 1.96 & 0.00 \\
\hline Personalisation & 93.46 & 3.92 & 2.61 \\
\hline Temporal Contiguity & 88.24 & 11.76 & 0.00 \\
\hline Voice & 85.62 & 0.00 & 14.38 \\
\hline Modality & 84.97 & 0.65 & 14.38 \\
\hline Redundancy & 82.35 & 13.07 & 4.58 \\
\hline Signalling & 70.59 & 29.41 & 0.00 \\
\hline Coherence & 61.44 & 26.80 & 11.76 \\
\hline Segmenting & 9.80 & 90.20 & 0.00 \\
\hline
\end{tabular}

Spatial and temporal contiguity were observed by all tutorials, with a small percentage only partially observed. No tutorial entirely failed to observe these principles. For temporal contiguity, this is arguably a consequence of basic screencast editing skills and the nature of screencasts generally. In most cases, screencasts involve narrating and demonstrating a particular procedure. It makes sense to narrate what you are demonstrating at the same time; at least this would be the default approach for most video instruction. In the small number of cases where temporal contiguity was only partially observed, this was usually a consequence of poor editing rather than design.

Personalisation had one of the highest rates of observance with almost all tutorials observing inclusive, personal language to some extent. In a number of instances, a precise, clear and slow manner of speaking was employed which although using inclusive language, 
struck me as relatively formal. In contrast there were other screencasts where the tone was more conversational and informal, yet both passed the test for personalisation. For contrasting approaches, see the screencasts "How to find company information using Factiva" (Massey University Library, 2014) and "Finding a book" (University of Canterbury Library, 2014). However, as mentioned above, research suggests that a minimum of inclusive language can have a positive effect and there is a risk of informality serving as a distraction rather than an enhancement (R. E. Mayer, 2014b, p. 363). Still, it would be interesting to see more work on what effect (if any) more or less conversational language has in a library instructional context.

Signalling also had universal observance, but with a greater amount of tutorials failing to fully observe the principle. This is possibly reflective of it requiring more advanced technical skills than simply preserving spatial and temporal contiguity. In short, all tutorials appeared to recognise the importance of signalling, but some failed to execute it fully. Mostly this was down to either poor encoding i.e. low resolution or small-screen videos that could not be enlarged, or imprecise positioning between what was being demonstrated and the signal used (e.g. arrow, highlight etc). In the case of poor encoding, this could also reflect a gap between the author's preferences and the person or team responsible for uploading and/or hosting it.

In terms of the voice principle, there were no tutorials that opted for a machine generated narrator in lieu of a human one. Thus, where a narrator was used, the voice principle was present by default. As can be seen in the results, tutorials opting for human narration represented a significant majority. Tutorials that failed to observe the voice principle opted for captions and/or signalling to support the on-screen images, rather than verbal narration. The modality principle was observed in similar proportions to the voice principle. This is to be expected as the two principles are both addressing the presence or absence of narration. Rather than looking at whether a human voice is used in narration though, the modality principle focuses on whether there was any verbal narration at all. The reason there is not absolute correlation between the two is that the modality principle was only partially 
observed for some tutorials; for example where verbal narration was intermittent, alternating with silent captioned explanation.

Redundancy was avoided for most tutorials, with only a small percentage duplicating the narration with on-screen captions. Some tutorials opted for some duplication, for example reading bulleted points on a slide verbatim, but moving to verbal narration alone for screen demonstrations (University of Auckland Library, 2012). With regard to those screencasts that did duplicate the narration with on-screen text, it is possible this was done (at least partially) for the benefit of hearing-impaired viewers. However, to avoid the impact of redundancy on other viewers it would be preferable to have captions as an option rather than the default.

Coherence was observed by the majority of tutorials, with a small percentage intermittently including extraneous material. A reasonable percentage (11.76\%) scored 0 on the rubric, featuring extraneous material throughout the entire tutorial. While this might seem surprising, it reflects, I think, an understandable attempt to make screencasts engaging. A common extraneous element observed within the tutorials, for example, was background music. There is certainly enough precedent for people to think that adding music to a multimedia presentation is a good strategy for generating interest. Advertising, for example, represents some of the most pervasive multimedia content we will encounter in daily life. You will rarely encounter a video advertisement that does not have some kind of background music or sound effects - for a contemporary sample see this compilation of 2015 Super Bowl advertisements (Crouch, 2015). Given that advertisers are in the business of creating short multimedia presentations that attempt to capture and sustain attention on key messages, it is unsurprising that screencast creators - consciously or otherwise - might echo some of these elements in creating multimedia presentations. However, this engagement, according to multimedia learning theory, may come at a detriment to effective learning. This is particularly going to be the case where cognitive load might be expected to be high, for example a) where the material is complex and or b) with novice learners (Clark \& Mayer, 2012). In contrast, the cognitive processing required to absorb the average advertising message is arguably relatively low. 
The segmenting principle had high partial observance, but few tutorials built this into their tutorials formally. All tutorials, at a minimum, gave the user the ability to control pacing through pause and navigation (skip forward or back) features; this is not surprising given that these features are available by default in most online video software. Far less common was the deliberate placement of pauses between stages or 'segments' of the lesson. In some cases, the simplicity of the tutorial arguably did not warrant it. Where the concept or procedure is simple with only a few elements, for example "Using the Library Catalogue" (University of Waikato Library, 2015), the chance of cognitive overload is probably low. In these instances, segmenting is unlikely to present much of a learning advantage.

\section{The Australian and New Zealand samples compared}

For most principles, there was little to separate the Australian from the New Zealand sample. Seven of the nine principles featured an average rating difference of around $5 \%$ or less in all categories (observed, partially observed, and not observed). In these instances, the observations made for the entire sample above also apply to the New Zealand and Australian samples independently. Screencasts from NZ institutions were highly represented in the top third of all tutorials however, accounting for 5 of the 9 universities featured and $74 \%$ of the screencasts in this range.

More significant differences were observed for the coherence and signalling principles.

\section{Coherence}

\begin{tabular}{|l|r|r|r|}
\hline Tutorial sample & Observed & Partially observed & Not observed \\
\hline Australian & 65.52 & 34.48 & 0.00 \\
\hline New Zealand & 60.48 & 25.00 & 14.52 \\
\hline
\end{tabular}

The difference here lies largely in the number of partial vs. non-observations, but also in the nature of the extraneous content.

In the Australian sample, the extraneous content was comprised entirely of images. As these were a comparatively minor proportion of the overall screencast, they resulted in a 'partially observed' rating. To give a specific example, in the case of Melbourne it was a themed graphic occurring across a number of tutorials (see Figure 1. below). This compromises the 
coherence principle by not directly supporting, and possibly serving as a distraction from the instructional message. It also compromises the signalling principle: by reducing the space available to display the instructional content, individual details are harder to make out. In a number of Queensland and Sydney cases, images of people (presumably students) were used to support the text or narration (see Figure 2. below). Presumably these were added to provide a more engaging and personalised presentation, but this comes at the risk of distraction from the essential instruction as research indicates (Mayer, 2009, pp. 95-98). There is some evidence to suggest that people can learn more effectively if an image of the narrator/instructor is used, but the results are mixed (Mayer, 2009, pp. 259-261). In any case, the above examples do not use the images specifically in this way.

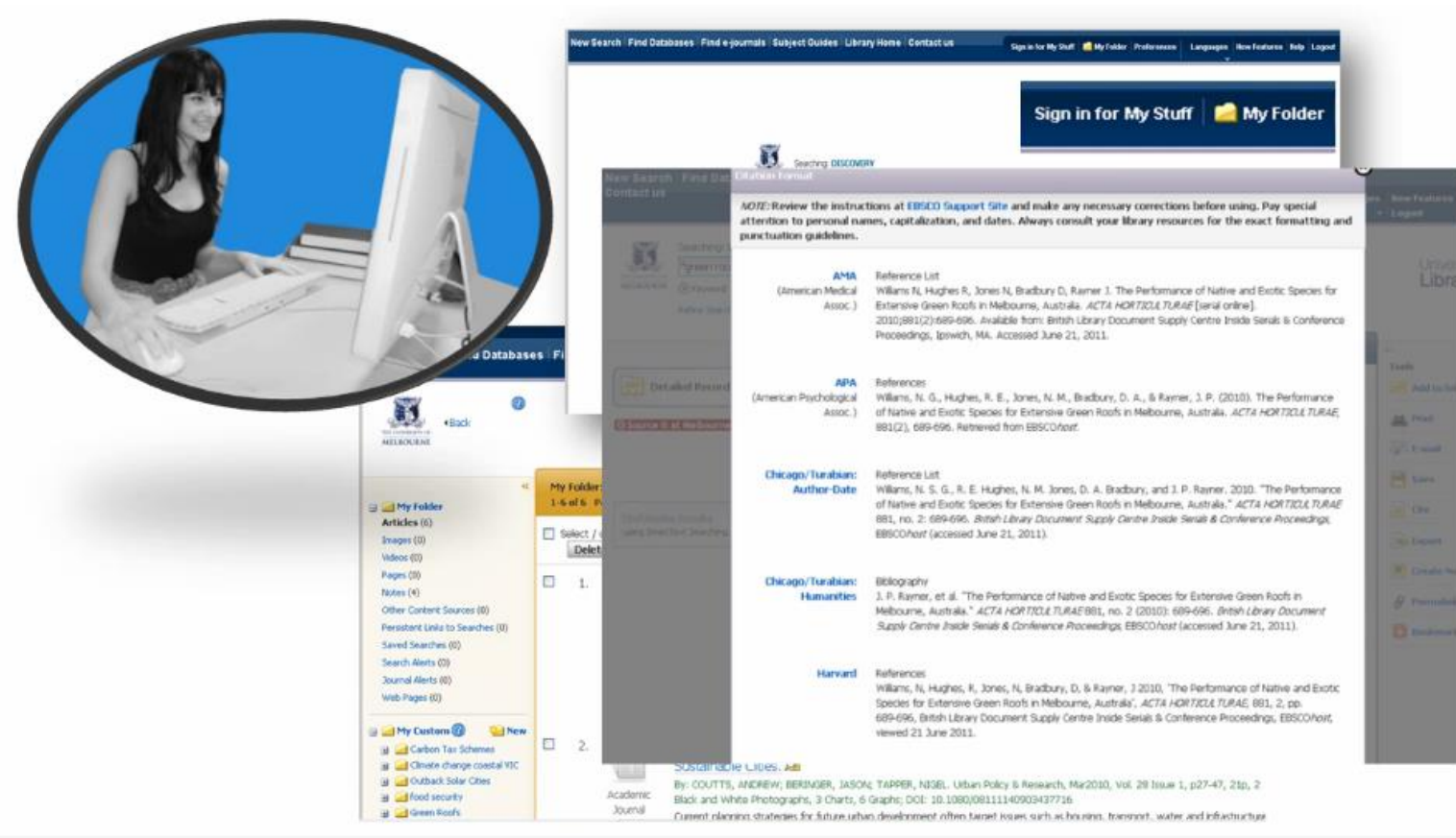

Figure 1. Screen capture from "Using Discovery for assignments at the University of Melbourne Library" (University of Melbourne Library, 2012) 
- Searching relevant health databases using subject headings

- Using database limits to filter search results to qualitative studies

Figure 2. Screen capture from "Your guide to finding qualitative health information." (University of Sydney Library, 2012)

In contrast, where the New Zealand examples included extraneous material, it was mostly used throughout the entire tutorial. Rather than extraneous images, in all 'not observed' cases this involved the use of background music throughout. Looking at the institutional level, the majority of these (15 of 19 screencasts) were from University of Otago. As such, this observation is more reflective of Otago's practice, rather than NZ universities as a whole. It is worth noting though, that this represents slightly less than half of the tutorials available from Otago at the time of this project. This seems to reflect a change of approach from Otago, as only tutorials from 2013 onwards feature background music. Music is absent from earlier tutorials spanning 2011-2012, though admittedly this is the also the case for two tutorials from 2014. As with extraneous images, providing background music risks splitting the attention of the learner, lessening the ability to focus on essential information.

Another common extraneous element, present in addition to background music and in isolation was the inclusion of synthetic mouse click and keystroke sounds. These accounted for the majority of partial observations in the NZ sample. Making up the remainder of partial observations were instances of intermittently distorted audio recordings which detracted from the verbal instruction. 


\section{Signalling}

\begin{tabular}{|l|r|r|r|}
\hline Tutorial sample & \multicolumn{2}{|l|}{ Observed } & \multicolumn{2}{l|}{ Partially observed } & Not observed \\
\hline Australian & 79.31 & 20.69 & 0.00 \\
\hline New Zealand & 67.74 & 32.26 & 0.00 \\
\hline
\end{tabular}

While both samples show a universal attempt at signalling, the difference lies in the higher proportion of partial observances for the NZ sample. The most common reason for a partial result (in both samples) was low-quality video encoding or the inability to expand the video to full-screen. In either scenario, the result is the same: it makes it difficult to see what is being signalled. In some cases this might be easily fixed by uploading it again at higher quality or to a platform that enables full-screen viewing e.g. YouTube.

\section{Individual institutions}

The low standard deviation (0.96) from the mean for individual institutions is encouraging. This reflects that most institutions in the sample were within approximately one point of the mean $(7.6 / 9)$

\section{Exemplars}

Approximately one third of the screencasts in the sample shared a score of 8.5 , with one tutorial scoring a maximum possible score of 9 . Interestingly, the 8.5 scoring tutorials all scored identically against the rubric, with a 1 for all principles save for segmenting, with 0.5 . This is not to say that these cannot be improved - these principles make no judgement on the informational content for example - just that they reflect a sound foundational approach to screencast design as informed by cognitive psychology. Other considerations will need to be brought to bear as appropriate to tailor the content and approach to the particular audience. See Appendix III for a selection of tutorials from those institutions scoring in the 8 to 9 range. 


\section{Conclusion}

This project has assessed screencasts produced by New Zealand and Australian University libraries against a set of multimedia learning principles. These principles, drawn from Mayer's Cognitive Theory of Multimedia Learning, are backed by evidence-based research and have been shown to contribute to effective learning.

Mayer's theory, or elements of it, has been discussed in best practice recommendations for library screencasts, but has not been used as the basis for an assessment rubric in this context. There has been research into online library tutorials within the New Zealand/Australian context, but few including screencasts and none (to my knowledge) focusing on screencasts exclusively. Determining the extent to which screencasts across these libraries reflect these best-practice principles gives an indication of their instructional potential from a cognitive psychological perspective and highlights possible areas for improvement.

Overall, it can be concluded that the screencasts produced by the universities surveyed strongly reflect effective multimedia learning principles. The low variance across the sample suggests this high standard was approximated or exceeded by most tutorials.

In terms of international comparison, the New Zealand and Australian samples were comparable overall, with each scoring close to the mean for all screencasts. In terms of relative adherence to the individual principles, both samples scored similarly. The principles with the greatest disparity were coherence and signalling. In the case of coherence, the disparity was largely driven by the practice of one institution's practice so should not be generalised as a regional trend.

Several areas for improvement can be identified based on the least frequently observed principles:

1. Coherence - screencast designers should be careful to avoid the temptation of text, images and audio that don't directly relate to the instruction

2. Segmenting - consider breaking up longer or multi-stage tutorials into smaller segments and provide a pause for learners to process the information; alternatively longer segments can be divided into separate tutorials 
3. Signalling - ensure videos are able to be viewed in full-screen and encoded and uploaded at a level that ensures clarity

\section{Further research}

One limitation of this research project is that it can only suggest whether or not screencast tutorials in this sample are effective in principle given Mayer et al.'s research into multimedia learning. One opportunity for extending this research would be to test the effectiveness of some of these tutorials in practice with an experimental test group. It would be interesting to see to what extent tutorials scoring high on the rubric were effective versus equivalent tutorials that consciously failed to observe particular principles.

More generally, there is an opportunity to test these multimedia principles within a library context. Much of the research examples given to support these principles come from science or engineering e.g. how lightning storms develop (Mayer, 2009, pp. 31-40). Also, although the principles themselves have a solid research base, there is some uncertainty as to what mitigating factors (if any) might apply. For example, the coherence principle is possibly most important for novice learners or those with a low working memory (Mayer, 2009 , p. 89). Segmenting stands out in this sample as a principle that was almost universally ignored, apart from the presence of user paced controls (pause, stop, review etc). This may be a perfectly adequate situation given the complexity of your average library tutorial, or it could be making things unnecessarily difficult. Similarly, as noted, most tutorials observed a minimum standard of personalisation. Yet there was some significant variance in just how personal or conversational the tone and language was. It would be interesting to see more work in this area, testing screencasts with less or more formal approaches with all other things being equal. Testing some of these 'boundary conditions' could help in determining whether some multimedia principles are more or less applicable to the library context and under which circumstances. This could extend to one or more of the principles omitted from this project e.g. pre-training.

Finally, as noted previously, some institutions appear to be moving away from screencasts toward more animation-based, interactive tutorials. If they are to supplant more typical screencast instruction, using a testing rubric like the one used in this study could uncover 
some of their comparative advantages or shortcomings. There is also scope here for seeing how they compare in an experimental setting against more typical screencast instruction. 


\section{Appendices}

\section{Appendix I: Coding manual for identifying design elements}

(Clark \& Mayer, 2011b; Mayer, 2008, 2009; R. E. Mayer, 2014c)

\section{Principles to Reduce Extraneous Processing:}

\begin{tabular}{|c|c|c|c|}
\hline Principle & Description & Example & Coding questions \\
\hline Coherence & $\begin{array}{l}\text { People learn better } \\
\text { when extraneous } \\
\text { material is excluded } \\
\text { rather than included }\end{array}$ & $\begin{array}{l}\text { Cut out interesting but } \\
\text { irrelevant text, graphics } \\
\text { and audio e.g. music } \\
\text { playing behind the } \\
\text { narration; animations } \\
\text { that are not essential to } \\
\text { the learning objective(s) }\end{array}$ & $\begin{array}{l}\text { Does everything } \\
\text { covered in the } \\
\text { screencast directly } \\
\text { relate to the } \\
\text { instructional task(s)? } \\
\text { 1: Yes - contains no } \\
\text { extraneous material } \\
0: \text { No - extraneous } \\
\text { material appears } \\
\text { throughout or for most } \\
\text { of the screencast e.g. } \\
\text { background music } \\
0.5 \text { No - contains some } \\
\text { extraneous material }\end{array}$ \\
\hline Redundancy & $\begin{array}{l}\text { People learn better } \\
\text { from graphics with } \\
\text { spoken words than } \\
\text { from graphics with } \\
\text { duplicated spoken } \\
\text { and printed words }\end{array}$ & $\begin{array}{l}\text { Avoid presenting } \\
\text { identical streams of } \\
\text { printed and spoken } \\
\text { words concurrently } \\
\text { with corresponding } \\
\text { animation. For example, } \\
\text { present words as } \\
\text { narration rather than as } \\
\text { narration and on-screen } \\
\text { text. } \\
\text { (i) Some redundancy is } \\
\text { acceptable where a) } \\
\text { captions are close to the } \\
\text { graphic they describe } \\
\text { and b) are limited to a } \\
\text { few words or c) there } \\
\text { are no graphics and the } \\
\text { combined captioning/ } \\
\text { narration is short } \\
\text { (Mayer, 2009, p. 130) }\end{array}$ & $\begin{array}{l}\text { Is unnecessary } \\
\text { duplication of narration } \\
\text { and text avoided?* } \\
\text { 1: Yes - no duplication } \\
\text { (see i) } \\
0: \text { No - full duplication } \\
0.5 \text { : Partially - some } \\
\text { duplication in excess of } \\
\text { the exceptions } \\
\text { indicated in (i) }\end{array}$ \\
\hline Signalling & $\begin{array}{l}\text { People learn better } \\
\text { when the essential } \\
\text { material and its } \\
\text { organization are }\end{array}$ & $\begin{array}{l}\text { Highlight essential } \\
\text { words and pictures e.g. } \\
\text { visually - enlarging or } \\
\text { highlighting key areas of }\end{array}$ & $\begin{array}{l}\text { Are important features } \\
\text { of the instruction } \\
\text { emphasised, verbally or } \\
\text { visually? }\end{array}$ \\
\hline
\end{tabular}




\begin{tabular}{|c|c|c|c|}
\hline & highlighted & $\begin{array}{l}\text { the screen or verbally - } \\
\text { using bold font or } \\
\text { spoken emphasis for key } \\
\text { words or concepts }\end{array}$ & $\begin{array}{l}\text { 1: Yes - key words } \\
\text { and/or images are } \\
\text { emphasised } \\
0: \text { No - no extra } \\
\text { emphasis on any aspect } \\
\text { of the instruction } \\
0.5 \text { Partially i.e. some } \\
\text { emphasis, but } \\
\text { inconsistent and/or } \\
\text { signalling is } \\
\text { compromised in some } \\
\text { way e.g. blurry or } \\
\text { indistinct, not clear } \\
\text { what is being signalled } \\
\text { or why }\end{array}$ \\
\hline Spatial Contiguity & $\begin{array}{l}\text { People learn } \\
\text { better when } \\
\text { corresponding } \\
\text { printed words and } \\
\text { graphics are } \\
\text { presented near each } \\
\text { other on the page } \\
\text { or screen. }\end{array}$ & $\begin{array}{l}\text { Place printed words } \\
\text { near corresponding } \\
\text { parts of graphics to } \\
\text { reduce the need for } \\
\text { visual scanning. For } \\
\text { example, put printed } \\
\text { words near } \\
\text { corresponding parts of } \\
\text { an illustration (on } \\
\text { paper) or animation (on } \\
\text { a screen). }\end{array}$ & $\begin{array}{l}\text { Is any accompanying } \\
\text { text placed in close } \\
\text { proximity to what is } \\
\text { being demonstrated in } \\
\text { the screencast? } \\
\text { 1: Yes or not applicable } \\
\text { (i.e. images have no } \\
\text { accompanying text) } \\
0: \text { No } \\
\text { 0.5: Partially i.e. } \\
\text { sometimes descriptive } \\
\text { text is close to the } \\
\text { image, sometimes not. }\end{array}$ \\
\hline Temporal Contiguity & $\begin{array}{l}\text { People learn better } \\
\text { when corresponding } \\
\text { words and pictures } \\
\text { are presented } \\
\text { simultaneously } \\
\text { rather than } \\
\text { successively. }\end{array}$ & $\begin{array}{l}\text { Present narration at the } \\
\text { same time as relevant } \\
\text { screenshots/images } \\
\text { rather than before or } \\
\text { after. }\end{array}$ & $\begin{array}{l}\text { Is any narration } \\
\text { presented at the same } \\
\text { time as what is being } \\
\text { demonstrated on } \\
\text { screen? } \\
\text { 1: Yes or not applicable } \\
\text { (i.e. there is no verbal } \\
\text { narration) } \\
0: \text { No. Narration and } \\
\text { images are presented } \\
\text { successively i.e. first } \\
\text { narration, then the } \\
\text { image or vice versa. } \\
0.5 \text { Partially i.e. } \\
\text { occasional } \\
\text { displacement between } \\
\text { narration and related } \\
\text { images on screen }\end{array}$ \\
\hline
\end{tabular}




\section{Principles for Managing Essential Processing}

\begin{tabular}{|c|c|c|c|}
\hline Principle & Description & Example & Coding Questions \\
\hline Segmenting & $\begin{array}{l}\text { People learn better } \\
\text { when a complex lesson } \\
\text { is presented in } \\
\text { manageable parts }\end{array}$ & $\begin{array}{l}\text { Allow time between } \\
\text { successive bite-size } \\
\text { segments. For } \\
\text { example, provide } \\
\text { pauses between new } \\
\text { concepts and allow the } \\
\text { viewer to control the } \\
\text { pace. }\end{array}$ & $\begin{array}{l}\text { Are there intentional } \\
\text { pauses between new } \\
\text { concepts or } \\
\text { instructional steps in } \\
\text { the screencast? Is the } \\
\text { learner otherwise able } \\
\text { to control the pacing } \\
\text { of the instruction e.g. } \\
\text { pause/play controls? } \\
1 \text { : Yes - there are } \\
\text { intentional pauses } \\
\text { between sections and } \\
\text { the viewer can } \\
\text { manually pause the } \\
\text { screencast } \\
0: \text { No - there are no } \\
\text { intentional pauses and } \\
\text { no controls to } \\
\text { manually pause } \\
0.5 \text { There are } \\
\text { intentional pauses but } \\
\text { no manual control OR } \\
\text { manual control but no } \\
\text { intentional pauses }\end{array}$ \\
\hline Modality & $\begin{array}{l}\text { People learn better } \\
\text { from a multimedia } \\
\text { presentation when } \\
\text { words are spoken } \\
\text { rather than printed }\end{array}$ & $\begin{array}{l}\text { Provide spoken-word } \\
\text { narration rather than } \\
\text { printed captions. }\end{array}$ & $\begin{array}{l}\text { Does the screencast } \\
\text { feature spoken-word } \\
\text { narration? } \\
1: \text { Yes } \\
0: \text { No } \\
0.5 \text { Contains some } \\
\text { narration, but some } \\
\text { sections only feature } \\
\text { printed captions. } \\
\text { Where both spoken- } \\
\text { word and captions are } \\
\text { present } \\
\text { simultaneously, mark it } \\
\text { a '1' } \\
\text { Any overload caused } \\
\text { by duplication of } \\
\text { spoken-word and } \\
\text { captions can be } \\
\text { addressed under the } \\
\text { Redundancy Principle. }\end{array}$ \\
\hline
\end{tabular}




\section{Principles for Fostering Generative Processing}

\begin{tabular}{|c|c|c|c|}
\hline Principle & Description & Example & Question \\
\hline Personalisation & $\begin{array}{l}\text { People learn better } \\
\text { from a multimedia } \\
\text { presentation when the } \\
\text { words are in a } \\
\text { conversational style } \\
\text { rather than a formal } \\
\text { style. }\end{array}$ & $\begin{array}{l}\text { Say "I" and "you" } \\
\text { rather than only use } \\
\text { third person } \\
\text { constructions, avoid } \\
\text { unexplained jargon }\end{array}$ & $\begin{array}{l}\text { Are words (narration or } \\
\text { text) presented in an } \\
\text { informal/conversational } \\
\text { style? } \\
1: \text { Yes - an informal } \\
\text { style is used throughout } \\
0: \text { No - a formal style is } \\
\text { used } \\
0.5: \text { Partially - the style } \\
\text { shifts between formal } \\
\text { and informal }\end{array}$ \\
\hline Voice & $\begin{array}{l}\text { People learn better } \\
\text { when the words in a } \\
\text { multimedia message } \\
\text { are spoken by a } \\
\text { friendly human voice } \\
\text { rather than a machine } \\
\text { voice. }\end{array}$ & $\begin{array}{l}\text { Use a recorded human } \\
\text { voice rather than } \\
\text { computer-generated } \\
\text { narration. }\end{array}$ & $\begin{array}{l}\text { If the screencast is } \\
\text { narrated, does it use a } \\
\text { recorded human voice? } \\
1: Y e s \\
0: \text { No/ No narration } \\
0.5: \text { Partially - there is a } \\
\text { mix of human and } \\
\text { computer-generated } \\
\text { narration }\end{array}$ \\
\hline
\end{tabular}


Appendix II: Observed principles by sample: raw numbers and percentages

\section{All Universities}

Raw numbers

\begin{tabular}{|l|r|r|r|}
\hline Principle & Present & Partially present & Not present \\
\hline Coherence & 94 & 41 & 18 \\
\hline Redundancy & 126 & 20 & 7 \\
\hline Signalling & 108 & 45 & 0 \\
\hline Spatial Contiguity & 150 & 3 & 0 \\
\hline Temporal Contiguity & 135 & 18 & 0 \\
\hline Segmenting & 15 & 138 & 0 \\
\hline Modality & 130 & 1 & 22 \\
\hline Personalisation & 143 & 6 & 4 \\
\hline Voice & 131 & 0 & 22 \\
\hline
\end{tabular}

\section{Australian Universities}

29 Tutorials

Raw Data

\begin{tabular}{|l|r|r|r|}
\hline Principle & Present & Partially present & Not present \\
\hline Coherence & 19 & 10 & 0 \\
\hline Redundancy & 25 & 4 & 0 \\
\hline Signalling & 23 & 6 & 0 \\
\hline Spatial Contiguity & 29 & 0 & 0 \\
\hline Temporal Contiguity & 25 & 4 & 0 \\
\hline Segmenting & 2 & 27 & 0 \\
\hline Modality & 26 & 0 & 3 \\
\hline Personalisation & 28 & 1 & 0 \\
\hline
\end{tabular}

\begin{tabular}{|l|r|r|r|}
\hline Percentages & Present & Partially present & Not present \\
\hline Coherence & 61.44 & 26.80 & 11.76 \\
\hline Redundancy & 82.35 & 13.07 & 4.58 \\
\hline Signalling & 70.59 & 29.41 & 0.00 \\
\hline Spatial Contiguity & 98.04 & 1.96 & 0.00 \\
\hline Temporal Contiguity & 88.24 & 11.76 & 0.00 \\
\hline Segmenting & 9.80 & 90.20 & 0.00 \\
\hline Modality & 84.97 & 0.65 & 14.38 \\
\hline Personalisation & 93.46 & 3.92 & 2.61 \\
\hline Voice & 85.62 & 0.00 & 14.38 \\
\hline
\end{tabular}

Percentages

\begin{tabular}{|l|r|r|r|}
\hline Principle & \multicolumn{1}{|c|}{ Present } & Partially present & Not present \\
\hline Coherence & 65.52 & 34.48 & 0.00 \\
\hline Redundancy & 86.21 & 13.79 & 0.00 \\
\hline Signalling & 79.31 & 20.69 & 0.00 \\
\hline Spatial Contiguity & 100.00 & 0.00 & 0.00 \\
\hline Temporal Contiguity & 86.21 & 13.79 & 0.00 \\
\hline Segmenting & 6.90 & 93.10 & 0.00 \\
\hline Modality & 89.66 & 0.00 & 10.34 \\
\hline Personalisation & 96.55 & 3.45 & 0.00 \\
\hline
\end{tabular}




\section{New Zealand Universities 124 Tutorials}

\begin{tabular}{|l|r|r|r|}
\hline Principle & Present & Partially present & Not present \\
\hline Coherence & 75 & 30 & 19 \\
\hline Redundancy & 101 & 16 & 7 \\
\hline Signalling & 84 & 40 & 0 \\
\hline Spatial Contiguity & 121 & 2 & 0 \\
\hline Temporal Contiguity & 109 & 15 & 0 \\
\hline Segmenting & 12 & 112 & 0 \\
\hline Modality & 105 & 1 & 18 \\
\hline Personalisation & 116 & 6 & 2 \\
\hline Voice & 106 & 0 & 18 \\
\hline
\end{tabular}

\begin{tabular}{|l|r|r|r|}
\hline Principle & \multicolumn{1}{|c|}{ Present } & Partially present & Not present \\
\hline Coherence & 60.48 & 24.19 & 15.32 \\
\hline Redundancy & 81.45 & 12.90 & 5.65 \\
\hline Signalling & 67.74 & 32.26 & 0.00 \\
\hline Spatial Contiguity & 97.58 & 1.61 & 0.00 \\
\hline Temporal Contiguity & 87.90 & 12.10 & 0.00 \\
\hline Segmenting & 9.68 & 90.32 & 0.00 \\
\hline Modality & 84.68 & 0.81 & 14.52 \\
\hline Personalisation & 93.55 & 4.84 & 1.61 \\
\hline Voice & 85.48 & 0.00 & 14.52 \\
\hline
\end{tabular}

Appendix III: High-scoring screencast examples

\begin{tabular}{|c|c|c|}
\hline Host Institution & Title of Tutorial & URL \\
\hline Auckland University of Technology & eBooks: Introduction to eBooks & http://bit.Iy/1IV9Hpp \\
\hline Australian National Library & Advanced Keyword Search_v2 of the ANU Library catalogue & http://bit.ly/1L9rz8J \\
\hline Massey University & Discover in detail & http://bit.Iy/1dVEBTD \\
\hline University of Canterbury & Understand your reading list & http://bit.Iy/1GZgEcC \\
\hline University of Melbourne & Navigating Discovery at the University of Melbourne Library & http://bit.Iy/1GyiyQw \\
\hline University of New South Wales & Installing EndNote for Mac & http://bit.Iy/1MUMYdP \\
\hline University of Otago & Google scholar medical search example & http://bit.Iy/11VdtPn \\
\hline University of Queensland & UQ Library Search & http://bit.Iy/1GZ3vgA \\
\hline University of Sydney & Advanced Searching in Informit Online & http://bit.ly/1TDt2Bh \\
\hline University of Waikato & Find eBooks - Library Search & http://bit.Iy/1LpH57M \\
\hline Victoria University of Wellington & Te Waharoa : Getting started & http://bit.ly/1dVE7wS \\
\hline
\end{tabular}

Possible improvements

Segmenting: no formal pausing or section breaks

Segmenting: no formal pausing or section breaks

Coherence: occasional synthetic keyboard / mouse click sounds; segmenting: no formal pausing or section breaks

Coherence: occasional keyboard / mouse click sounds; signaling: occasional screenshot too small to see what is being signalled; segmenting: no formal pausing or section breaks Segmenting: no formal pausing or section breaks

Temporal contiguity: sometimes explanation does not coincide with what is being demonstrated

Segmenting: no formal pausing or section breaks; signalling: transitions occasionally too quick to see what was signalled

Coherence: occasional synthetic keyboard / mouse click sounds; segmenting: no formal. pausing or section breaks

Coherence: occasional synthetic keyboard / mouse click sounds

Find eBooks - Library Search

Segmenting: no formal pausing or section break

$\begin{array}{lll}\text { Victoria University of Wellington } & \text { Te Waharoa: Getting started } & \text { http://bit.ly/1dVE7wS }\end{array}$ Segmenting: no formal pausing or section breaks 


\section{References}

Anderson, K., \& May, F. A. (2010). Does the method of instruction matter? An experimental examination of information literacy instruction in the online, blended, and face-toface classrooms. The Journal of Academic Librarianship, 36(6), 495-500. doi: http://dx.doi.org/10.1016/j.acalib.2010.08.005

Arant-Kaspar, W., \& Benefiel, C. (2008). Drive-by BI: Tailored in-class mini-instruction sessions for graduate and upper-level undergraduate courses. Reference Services Review, 36(1), 39-47. doi: 10.1108/00907320810852014

Betty, P. (2008). Creation, management, and assessment of library screencasts: The Regis Libraries Animated Tutorials Project. Journal of Library Administration, 48(3-4), 295315. doi: $10.1080 / 01930820802289342$

Blummer, B. A., \& Kritskaya, O. (2009). Best practices for creating an online tutorial: A literature review. Journal of Web Librarianship, 3(3), 199-216. doi: $10.1080 / 19322900903050799$

Bowles-Terry, M., Hensley, M. K., \& Hinchliffe, L. J. (2010). Best practices for online video tutorials in academic libraries: A study of student preferences and understanding. Communications in Information Literacy, 4(1), 17-28.

Bryman, A. (2012). Social research methods (4th ed.). Oxford, UK: Oxford University Press.

Clark, R. C., \& Mayer, R. E. (2011a). Applying the personalization principle. E-learning and the science of instruction: Proven guidelines for consumers and designers of multimedia learning (pp. 179-203). San Francisco, CA: Pfeiffer.

Clark, R. C., \& Mayer, R. E. (2011b). E-learning and the science of instruction: Proven guidelines for consumers and designers of multimedia learning. San Francisco, CA: Pfeiffer.

Clark, R. C., \& Mayer, R. E. (2012). Applying the coherence principle: Adding material can hurt learning. E-learning and the science of instruction. (pp. 150-176). San Franscisco, CA.: Pfeiffer.

cognitive psychology. (2015) in Encyclopaedia Britannica. Retrieved from http://www.britannica.com/science/cognitive-psychology 
Cooperstein, S. E., \& Kocevar-Weidinger, E. (2004). Beyond active learning: A constructivist approach to learning. Reference Services Review, 32(2), 141-148. doi: $10.1108 / 00907320410537658$

Cordes, M. J. (2011). Literature and practice in the creation of online information literacy tutorials in New Zealand and Australian university libraries: Results of content analysis of online tutorials. (Unpublished MLIS research project, Victoria University of Wellington, 2011). Retrieved from http://researcharchive.vuw.ac.nz/xmlui/handle/10063/1954

Crouch, I. (2015). The best and worst Super Bowl ads of 2015. Retrieved 30/05/2015, from http://www.newyorker.com/business/currency/best-worst-super-bowl-ads-2015

Deakin University (Producer). (2013). Stay up to date with new research. [Video file] Retrieved from http://air.deakin.edu.au/public/media/Research+Support++Stay+up+to+date+\%28part+1\%29/0_7ekj6nye

Dewan, P., \& Steeleworthy, M. (2013). Incorporating online instruction in academic libraries: Getting ahead of the curve. Journal of Library \& Information Services in Distance Learning, 7(3), 278-296. doi: 10.1080/1533290X.2013.804020

Ergood, A., Padron, K., \& Rebar, L. (2012). Making library screencast tutorials: Factors and processes. Internet Reference Services Quarterly, 17(2), 95-107. doi: $10.1080 / 10875301.2012 .725705$

Good, R. (2006). What is screencasting? An interview with Jon Udell. Retrieved October 20, 2014 , from http://www.masternewmedia.org/news/2006/05/02/what_is_screencasting_an_int erview.htm

Group of Eight Australia. (2014). Member information. Retrieved October 20, 2014, from https://go8.edu.au/page/member-information

Guo, P. J., Kim, J., \& Rubin, R. (2014). How video production affects student engagement: an empirical study of MOOC videos. Paper presented at the Proceedings of the first ACM conference on Learning @ scale conference, Atlanta, Georgia, USA. http://dl.acm.org/citation.cfm?doid=2556325.2566239

Hess, A. N. (2013). The MAGIC of web tutorials: How one library (re)focused its delivery of online learning objects on users. Journal of Library \& Information Services in Distance Learning, 7(4), 331-348. doi: 10.1080/1533290X.2013.839978 
Loch, B., Jordan, C. R., Lowe, T. W., \& Mestel, B. D. (2013). Do screencasts help to revise prerequisite mathematics? An investigation of student performance and perception. International Journal of Mathematical Education in Science and Technology, 45(2), 256-268. doi: 10.1080/0020739X.2013.822581

Loch, B., \& McLoughlin, C. (2011). An instructional design model for screencasting: Engaging students in self-regulated learning. Paper presented at the Ascilite 2011 : changing demands, changing directions.

Massey University Library (Producer). (2014). How to find company information using Factiva. [Video file.] Retrieved from https://connect.massey.ac.nz/factivacompanies

Mayer, R. E. (2008). Applying the science of learning: Evidence-based principles for the design of multimedia instruction. American Psychologist, 63(8), 760-769. doi: http://dx.doi.org/10.1037/0003-066X.63.8.760

Mayer, R. E. (2009). Multimedia learning. Cambridge; New York: Cambridge University Press. Mayer, R. E. (2011a). Applying the science of learning to multimedia instruction. In P. M. Jose \& H. R. Brian (Eds.), Psychology of Learning and Motivation (Vol. 55, pp. 77108): Academic Press.

Mayer, R. E. (2011b). Instruction based on visualizations. In R. E. Mayer \& P. A. Alexander (Eds.), Handbook of research on learning and instruction (pp. 427-442). New York: Routledge.

Mayer, R. E. (2014a). Multimedia instruction. In J. M. Spector, M. D. Merrill, J. Elen \& M. J. Bishop (Eds.), Handbook of research on educational communications and technology (pp. 385-399). New York: Springer

Mayer, R. E. (2014b). Principles based on social cues in multimedia learning: Personalization, voice, image, and embodiment principles. In R. E. Mayer (Ed.), The Cambridge Handbook of Multimedia Learning. (pp. 345-368). New York: Cambridge University Press.

Mayer, R. E. (2014c). Research-based principles for designing multimedia instruction. In V. Benassi, C. E. Overson \& C. M. Hakala (Eds.), Applying science of learning in education : infusing psychological science into the curriculum (pp. 59-70). Retrieved from

http://bibpurl.oclc.org/web/70259http://teachpsych.org/Resources/Documents/ebo oks/asle2014.pdf. 
Mayer, R. E., ed. (2014). The Cambridge handbook of multimedia learning. New York: Cambridge University Press.

Mayer, R. E., \& Moreno, R. (2002). Aids to computer-based multimedia learning. Learning and Instruction, 12(1), 107-119. doi: http://dx.doi.org/10.1016/S09594752(01)00018-4

Mestre, L. (2012). Designing effective library tutorials: a guide for accommodating multiple learning styles. Oxford, UK: Elsevier.

Morris, C., \& Chikwa, G. (2014). Screencasts: How effective are they and how do students engage with them? Active Learning in Higher Education, 15(1), 25-37. doi: $10.1177 / 1469787413514654$

Morrison, G. R., Ross, S. M., Kalman, H. K., \& Kemp, J. E. (2013). Designing effective instruction. Hoboken, NJ: Wiley.

Notess, G. R. (2005). Casting the net: Podcasting and screencasting. Online, 29(6), 43-45. Universities New Zealand - Te Pōkai Tara. (2014). The NZ University System. Retrieved October 20, 2014, from http://www.universitiesnz.ac.nz/nz-university-system

Oehrli, J. A., Piacentine, J., Peters, A., \& Nanamaker, B. (2011). Do screencasts really work? Assessing student learning through instructional screencasts. Paper presented the ACRL 2011 Conference.

Oud, J. (2009). Guidelines for effective online instruction using multimedia screencasts. Reference Services Review, 37(2), 164-177. doi: 10.1108/00907320910957206

Plumb, T. K. (2010). Creating electronic tutorials: On your mark, get set, go! Journal of Electronic Resources Librarianship, 22(1-2), 49-64. doi: $10.1080 / 1941126 X .2010 .486729$

Raftery, D. (2011). Developing educational screencasts: A practitioner's perspective Instructional design : concepts, methodologies, tools and applications (Vol. 2, pp. 665-678). Hershey, PA: Information Science Reference.

Reed, S. K. (2006). Cognitive architectures for multimedia learning. Educational Psychologist, 41(2), 87-98. doi: 10.1207/s15326985ep4102_2

Scales, B. J., Nicol, E., \& Johnson, C. M. (2014). Redesigning comprehensive library tutorials: Theoretical considerations for multimedia enhancements and student learning. Reference \& User Services Quarterly, 53(3), 242-252. 
Scholz, A. M., Kerr, R. C., \& Brown, S. K. (1996). PLUTO: Interactive instruction on the web. College and Research Libraries News, 57(6), 346-349.

Silber, K. H. F. W. R. (2010). Handbook of improving performance in the workplace. (Vol. 1). San Francisco, CA: Pfeiffer.

Silver, S. L., \& Nickel, L. T. (2005). Are online tutorials effective? A comparison of online and classroom library instruction methods. Research Strategies, 20(4), 389-396. doi: http://dx.doi.org/10.1016/j.resstr.2006.12.012

Slebodnik, M., \& Riehle, C. F. (2009). Creating online tutorials at your libraries: Software choices and practical implications. Reference \& User Services Quarterly, 49(1), 33-37, 51.

Small, J. (2010). Delivering library instruction with screencast software: A Jing is worth a thousand words. Health Inform, 19(3), 15-20.

Smith, S. S. (2010). Web-based instruction: a guide for libraries. Chicago: American Library Association

Somoza-Fernández, M., \& Abadal, E. (2009). Analysis of web-based tutorials created by academic libraries. The Journal of Academic Librarianship, 35(2), 126-131. doi: http://dx.doi.org/10.1016/j.acalib.2009.01.010

Stiwinter, K. (2013). Using an interactive online tutorial to expand library instruction. Internet Reference Services Quarterly, 18(1), 15-41. doi: $10.1080 / 10875301.2013 .777010$

Su, S.-F., \& Kuo, J. (2010). Design and development of web-based information literacy tutorials. The Journal of Academic Librarianship, 36(4), 320-328. doi: http://dx.doi.org/10.1016/j.acalib.2010.05.006

Sugar, W., Brown, A., \& Luterbach, K. (2010). Examining the anatomy of a screencast: Uncovering common elements and instructional strategies. International Review of Research in Open \& Distance Learning, 11(3), 1-20.

Tempelman-Kluit, N. (2006). Multimedia learning theories and online instruction. College \& Research Libraries, 67(4), 364-369.

Tewell, E. (2010). Video tutorials in academic art libraries: A content analysis and review. Art Documentation: Journal of the Art Libraries Society of North America, 29(2), 53-61. doi: $10.2307 / 27949554$ 
Udell, J. (2004a). Making movies of software. Retrieved October 20, 2014, from http://jonudell.net/udell/2004-11-12-making-movies-of-software.html

Udell, J. (2004b). Name that genre: screencast. Retrieved October 20, 2014, from http://jonudell.net/udell/2004-11-17-name-that-genre-screencast.html University of Auckland Library (Producer). (2012). How to find recommended readings. [Video file.] Retrieved from http://flexiblelearning.auckland.ac.nz/finding-itemsfrom-reading-list/files/rec_readings_final_april.mp4

University of Canterbury Library (Producer). (2014). Finding a book. [Video file.] Retrieved from http://www.youtube.com/watch?v=GuYg-doR_q0\&list=UUI9mOj6_TySJ7HSQcTXKRw

University of Melbourne Library (Producer). (2012). Using Discovery for assignments at the University of Melbourne Library. [Video file.] Retrieved from https://vimeo.com/26557257

University of New South Wales Library (Producer). (2015). Research consultations at UNSW Library. [Video file] Retrieved from https://www.youtube.com/watch?v=bKCDexMAy9c\&index=7\&list=PLvW1evjftfvmc4 MO7hQ4MswzueK5Bc_3q

University of Sydney Library (Producer). Find that book! [Video file] Retrieved from http://www.library.usyd.edu.au/skills/elearning/learn/findbook/index.php University of Sydney Library (Producer). (2012). Your guide to finding qualitative health information. [Video file.] Retrieved from http://www.library.usyd.edu.au/skills/tutorials/nursing/findingqual/

University of Waikato Library (Producer). (2015). View in Catalogue. Retrieved from http://www.youtube.com/watch?v=K8Ka2kOBhhU

Zhang, L., Watson, E. M., \& Banfield, L. (2007). The efficacy of computer-assisted instruction versus face-to-face instruction in academic libraries: A systematic review. The Journal of Academic Librarianship, 33(4), 478-484. doi: http://dx.doi.org/10.1016/j.acalib.2007.03.006 